\section{National Biometry Audit II}

RP Gale 1 , N Saha ${ }^{2}$ and RL Johnston ${ }^{3}$

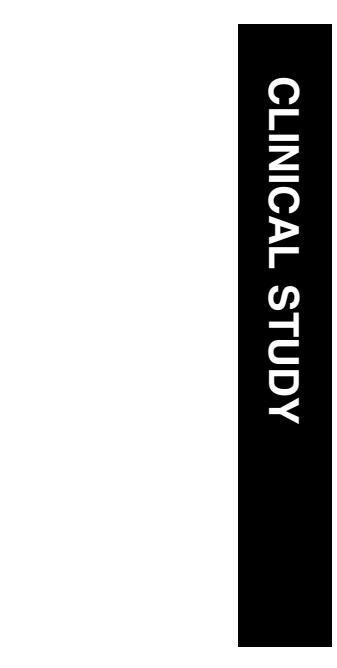

The quality of a biometry service is best judged by the percentage of eyes achieving a postoperative spherical equivalent refraction within \pm 0.5 or 1.0 dioptres of the target refraction and the total range of prediction error. The Royal College of Ophthalmologists (RCOphth) biometry guidelines published in 2001 are a practical, evidence-based, resource for helping eye departments achieve a satisfactory standard of prediction error. ${ }^{1}$ The guidelines deal with all aspects of a biometry service, from the personnel involved in running the service, the appropriate training they should receive, the intraocular lens (IOL) calculation formulae that should be used depending on the axial length of the eye and appropriate audit of the service. Evidence from clinical studies have shown that if the guidelines on formulae are applied and in addition A constants are customised and immersion ultrasound or partial coherence interferometry is used for axial length measurement then more than $90 \%$ of eyes would achieve a prediction error of $<1.0$ dioptre. $^{2-4}$ This standard far exceeds what most departments in the United Kingdom (UK) are currently delivering when using a single formula for all eyes without customising A constants. 5

The first National Biometry Audit performed in 2002 and published in Eye in January 2004 concluded that there was very poor awareness and implementation of the guidelines with only $4 \%$ of eye departments fully complying with the recommendations regarding IOL calculation formulae. ${ }^{6}$ In addition, this audit highlighted that customising A constants and setting a benchmark standard for prediction error should be included in the guidelines. It can be concluded from the results of the last survey that the greatest cause of prediction error in the
${ }^{1}$ Department of Ophthalmology, York Hospital, York, UK

${ }^{2}$ Department of Ophthalmology, Royal Victoria Hospital, Newcastle, UK

${ }^{3}$ Gloucestershire Eye Department, Cheltenham General Hospital, Sandford Road, Cheltenham, UK

Correspondence: RL Johnston, Gloucestershire Eye Department, Cheltenham General Hospital, Sandford Road, Cheltenham GL53 7AN, UK Tel: + 441242 272529; Fax: + 441242272585 E-mail: rob.johnston@ egnhst.org.uk

Received: 28 July 2004 Accepted in revised form: 21 October 2004 Published online: 29 April 2005

Financial interest declaration: Robert Johnston is a Director of Medisoft Limited. This work was presented at the Royal College of Ophthalmologists Congress, Manchester 2004 
National Health Service (NHS) is failure to apply appropriate IOL calculation formulae, modern methods of axial length measurement and customised A constants.

The primary aim of this second National Biometry Survey was to assess the change in implementation of the RCOphth biometry guidelines and to quantify the adoption of modern methods of axial length measurement and customisation of A constants in the NHS.

\section{Materials and methods}

Every ophthalmic department in the UK was contacted by telephone and a single member of staff who actually performs biometry was invited to participate in a structured questionnaire. The nature and purpose of the study was explained and the person was reassured that the data collected would be anonymous. If they agreed to participate a short interview was conducted to determine: the type of staff performing biometry, what training they had received, what equipment was routinely used, which formulae were applied, and the basis on which the formulae varied, whether A constants were customised and knowledge of audit results. Depending upon the responses of the participants a minimum of 9 and a maximum of 14 questions were asked (Appendix A). If no biometrist was available to be interviewed, then a further single follow-up call was made.

\section{Results}

All 178 NHS Ophthalmology Units in the UK were contacted. A biometrist was available to be interviewed in $94(53 \%)$ departments and in only one case did a biometrist refuse to be interviewed.

\section{Personnel}

Nurses are the most common group of healthcare professionals to routinely perform biometry and they alone were responsible for the service in $62(67 \%)$ UK ophthalmology departments. Nurses performed the task either alone or in combination with other health care professionals in $77(82 \%)$ departments. Orthoptists were the next most common group to perform biometry as a sole group of professionals and do so in nine (10\%) units. Junior doctors perform this role in two (3\%) departments as the only responsible group but in eight (9\%) departments routinely do so in combination with other health care professionals. The remaining departments used one or more of the following professional groups: an optometrist, an electrophysiologist, a technician, or a consultant ophthalmologist.

\section{Biometry training}

In-house training was the sole source of education for 37 (39\%) of the biometrists interviewed. Four $(4 \%)$ of the biometrists had most of their training from a representative of the manufacturer of the biometry equipment. Seven (7\%) units had sent a member of staff on an external biometry course as the sole method of training; however, 42 (45\%) used external courses in combination with in-house and/or manufacturers representative training to educate their staff.

\section{Biometry equipment}

Noncontact biometry (partial coherence laser interferometry, PCLI) was the routine form of axial length measurement in 57 (61\%) UK ophthalmology departments. Contact ultrasound was used as the sole method of measurement in 37 (39\%) of departments.

Immersion biometry was being routinely performed in one department and its role was being investigated in three others.

\section{IOL formulae}

The range of biometry formula routinely used in UK ophthalmology departments includes: SRK-T, SRK-II, Hoffer Q, Holladay, Haigis, and Binkhorst. The SRK-T formula was used solely in 17 (18\%) departments. The combination of SRK-T, Hoffer Q, and Holladay formulae was used in 28 (30\%) of departments and was the most frequently used combination used within a department. No departments were using SRK-II as a sole biometry formula; however, five (5\%) were still using if in combination with others.

\section{Customisation of ' $A$ ' constants}

In $44(47 \%)$ ophthalmology departments, a biometrist claimed that the A constants had been customised. The biometrists, however, were unable to recall accurately whether customisation was either specifically for the department, surgeon, PCLI or ultrasound. Biometrists were unsure if the A constant had been changed because of local audit or 'customised' because of a search on Internet websites.

\section{Royal College of Ophthalmology Guidelines}

A total of $67(71 \%)$ of the biometrists interviewed had read the RCOphth guidelines on biometry. 


\section{Audit}

In total, $73(78 \%)$ of those biometrists that were interviewed reported that regular audit of the predictability of the refractive outcome was performed in their department. In 50 of these 73 departments, the results of the audit were communicated back to the biometrists. In 19 (20\% of the total) departments, biometrists were able to remember a percentage of eyes achieving a final refraction within 1 dioptre of the predicted as a result of departmental audit. The range of this percentage was between 70 and $98 \%$.

\section{Discussion}

This study shows that there has been a significant improvement in the awareness and implementation of all aspects of the RCOphth biometry guidelines over the last 2 years.

In relation to the personnel performing biometry, the guidelines state that it is inappropriate for junior doctors to perform routinely this task and the percentage of departments where this is the case has fallen from 15 to $9 \%$ over the last 2 years. Nursing staff are increasingly taking on this role and they are now the sole provider of this service in $67 \%$ of departments compared with $58 \%$ 2 years ago. The guidelines recommend training of staff that perform biometry and in this survey $45 \%$ had been on an external training course compared with $37 \%$

2 years ago. Conversely, the percentage receiving only inhouse training has fallen from 48 to $39 \%$.

The RCOphth guidelines on the use of different IOL calculation formulae depending on the axial length of the eye are based on Hoffer's 1993 paper (Table 1). In all, $30 \%$ of departments now use this combination of formulae compared with 15\% 2 years ago, although it is not certain whether they are used as recommended. The obsolete SRK-II formula is only used in 5\% of departments now compared with $17 \% 2$ years ago.

The 2001 guidelines did not recommend as to which method of axial length measurement is to be used but this survey has revealed a major change in practice over the last 2 years. PCLI axial length measurement is now

Table 1 The Royal College of Ophthalmologists-recommended IOL calculation formulae depending on the axial length of the eye

\begin{tabular}{ll}
\hline Axial length $(\mathrm{mm})$ & Recommended formula \\
\hline$<22.0$ & Hoffer Q \\
$22.0-24.5$ & Average of SRK-T, Hoffer Q, and Holladay \\
$24.6-26.0$ & Holladay \\
$>26.0$ & SRK-T \\
\hline
\end{tabular}

routinely used in almost two-thirds of eye departments $(61 \%)$ compared with one-third (35\%) 2 years ago. All other eye departments routinely use contact ultrasound except one that uses immersion ultrasound.

The PCLI has the potential to improve prediction error because it has a higher resolution compared with a standard $10-\mathrm{MHz}$ ultrasound transducer $\left(0.012 \mathrm{~mm}^{8}\right.$ compared with $0.10-0.12 \mathrm{~mm}^{9}$ ) and is highly reproducible to $0.02 \mathrm{~mm} .{ }^{10}$ PCLI and ultrasound rely on fundamentally different principles to measure the axial length and despite correction factors in the PCLI software to allow for the different distances that are actually measured (to the retinal pigment epithelium in the case of PCLI and to the internal limiting membrane in the case of ultrasound) different ' $\mathrm{A}$ ' constants are required for the same IOL when using either technique. ${ }^{11}$ The PCLI is limited in its ability to measure axial length in circumstances such as very dense cataracts however and therefore requires the support of ultrasound axial length measurement as a second-line instrument.

Contact ultrasound is not as accurate as immersion ultrasound because applanation shallows the anterior chamber by an average of $0.14 \mathrm{~mm} .{ }^{11}$ Immersion ultrasound avoids this corneal compression, and with modern equipment it can be performed with the patient sitting almost upright rather than lying flat as was necessary in the past. During immersion ultrasound, two corneal spikes are seen compared with one during contact ultrasound biometry. These two spikes can be aligned making it is easier to judge if the measurement is being made on axis compared with contact ultrasound.

Customisation of A constants is important to eliminate systematic errors that may arise due to differences in the method of axial length measurement or due to incorrect manufacturer's A constants. Customised A constants for the same IOL when using PCLI or ultrasound axial length measurement can differ by more than 1.0 dioptre. ${ }^{12}$ It is encouraging that almost half $(47 \%)$ of the departments that were surveyed in 2004 claimed to customise A constants, but few of the biometrists were aware whether this was based on local audit of results or by consulting web sites. ${ }^{12}$ They were also unaware whether it was done separately for PCLI and ultrasound biometry. If individual surgeons within a department are using the same technique for cataract surgery, it is probably sufficient for a department to customise ' $\mathrm{A}$ ' constants rather than each individual.

A higher number of departments are now conducting regular audit of refractive outcomes as recommended in the RCOphth guidelines (78 vs $71 \% 2$ years ago). Only a small minority of biometrists, however, are able to remember details of the percentage of eyes achieving a prediction error of less than 1.0 dioptre (20 vs $16 \% 2$ years ago). 
In conclusion, the awareness and implementation of RCOphth biometry guidelines has substantially improved over the last 2 years and this is likely to significantly improve the predictability of the refractive result of cataract surgery in the UK. We recognise that the responses of the biometrists to the questions posed may be influenced by recall bias; however, this was also true for the first National Biometry Audit. The substantial improvements noted in this study compared with 2 years ago are therefore likely to be real. It is essential that the guidelines are updated to recommend current best practice, including the use of PCLI axial length measurement whenever possible and immersion ultrasound for the remaining eyes. They must also stress the importance of customising A constants for each IOL model and method of axial length measurement. Finally, biometry is about delivering a predictable result and it is imperative for the RCOphth to establish a benchmark standard in terms of the percentage of eyes achieving a final refraction within 1.0 dioptre of the target. This should be set at $85-90 \%$, and if this standard is achieved it is perhaps of less importance as to what methods were used to achieve it.

\section{References}

1 The Royal College of Ophthalmologists. Cataract Surgery Guidelines. www.rcophth.ac.uk. February 2001.

2 Percival SP, Vyas AV, Setty SS, Manvikar S. The influence of implant design on accuracy of postoperative refraction. Eye 2002; 16(3): 309-319.

3 Rajan MS, Keilhorn I, Bell SA. Partial coherence laser interferomerty versus ultrasound biometry in intraocular lens power calculations. Eye 2002; 16(5): 552-556.

4 Packer M, Fine IH, Hoffman RS, Coffman PG, Brown LK. Immersion A-scan compared with partial coherence interferometry: outcomes analysis. J Cataract Refract Surg 2002; 28(1): 239-242.

5 Murphy C, Tuft SJ, Minassian DC. Refractive error and visual outcome after cataract extraction. J Cataract Refract Surg 2002; 28(1): 62-66.

6 Gale RP, Saha N, Johnston RL. National Biometry Audit. EYE 2004; 18(1): 63-66.

7 Hoffer JK. The Hoffer Q formula: a comparison of theoretic and regression formulas. J Cataract Refract Surg 1993; 19: 700-712.

8 Findl O, Drexler W, Menapace R, Hitzenberger CG, Fercher AF. High precision biometry of pseudophakic eyes using partial coherence interferometry. J Cataract Surg 1998; 24: 1087-1093.

9 Schachar RA, Levy NS, Bonney RC. Accuracy of intraocular lens powers calculated from A-scan biometry with the Echo-oculometer. Ophthalmic Surg 1980; 11: 856-858.

10 Vogel A, Dick B, Krummenauer F. Reproducibility of optical biometry using partial coherence interferometry.
Intraobserver and intrerobserver reliability. J Cataract Refract Surg 2001; 27: 1961-1968.

11 Olsen T, Neilson PJ. Immersion versus contact technique in the measurement of axial length by ultrasound. Acta Ophthalmol 1989; 67: 101-102.

12 The User Group for Laser Interference Biometry. http:// www.uni-wuerzburg.de/augenklinik

\section{Appendix A}

Following are the questions asked to biometrists in the survey. Questions marked with an asterisk were additional depending upon a positive response from the previous questioning.

1. Which groups of health care professional routinely perform biometry in your department?

2. What type of training did you receive in the use of the biometry equipment?

3. What machines are used to measure the axial length of the eye in your department and which is routinely used?

4. Does your department use the immersion ultrasound technique?

5. In your department, which biometry formulae are used to calculate the required power of the IOL?

6. Have the 'A' constants been customised for the intraocular lenses within the department?

7. If the answer is yes to Question 6, how have they been customised (for the department or individual surgeon, Partial Coherence Laser Interferometer or ultrasound, by audit or literature gathering.)*

8. Does the biometry formula used depend upon the axial length of the eye?

9. As a biometrist within your department, have you read the Royal College of Ophthalmologists biometry formulae guidelines?

10. Is your department routinely performing audit comparing the predicted and post-operative spherical equivalent refractive outcome?

11. If the answer is yes to Question 10, have the results been communicated back to you as a biometrist?*

12. If the answer is yes to Question 11, can you recall the percentage of patients achieving a final refraction within 1 dioptre of the predicted refraction?*

13. If the answer is yes to Question 10, are there any problems that were highlighted by the audit?*

14. If there were any problems highlighted in response to Question 14, what changes have been implemented?* 